DOI 10.1007/s11223-017-9884-2

Strength of Materials

\title{
RETRACTED ARTICLE: FATIGUE ASSESSMENT OF Ti-6Al-4V \\ CIRCULAR NOTCHED SPECIMENS PRODUCED BY SELECTIVE LASER \\ MELTING
}

S. M. J. Razavi, ${ }^{\text {a }}$ P. Ferro,

UDC 539.4 and F. Berto ${ }^{\mathrm{a}, 1}$

The authors are retracting this article because it has already been published [1]. All authors agree with this retraction.

1. Razavi, SMJ, Ferro P. Berto F. Fatigue Assessment of Ti-6Al-4V Circular Notched Specimens Produced by Selective Laser Melting. Metals 2017, 7(8), 291

The online version of this article contains the full text of the retracted article as electronic supplementary material.

Electronic supplementary material. The online version of this article (doi:10.1007/s11223-017-9884-2) contains supplementary material, which is available to authorized users.

${ }^{\mathrm{a}}$ Department of Mechanical and Industrial Engineering, Norwegian University of Science and Technology (NTNU), Trondheim, Norway ( ${ }^{1}$ filippo.berto@ntnu.no). ${ }^{b}$ Department of Engineering and Management, University of Padova, Vicenza, Italy. Translated from Problemy Prochnosti, No. 3, pp. 105 - 114, May - June, 2017. Original article submitted December 12, 2016. 